\title{
Necrose avascular bilateral da cabeça femoral em paciente com Lúpus eritematoso sistêmico associado à corticoterapia prolongada: Relato de Caso
}

\author{
Femoral head bilateral avascular necrosis in a patient with systemic erythematosus lupus associated \\ with prolonged corticosteroid therapy: Case report
}

Robert Alves da Silva ${ }^{* \dagger}$, Amanda Cristina Morais da Silva*, Carlos Eduardo Cardoso ${ }^{\S}$

Como citar esse artigo. da Silva, R.A.; da Silva, A.C.M. Cardoso, C.E. Necrose avascular bilateral da cabeça femoral em paciente com Lúpus eritematoso sistêmico associado à corticoterapia prolongada: Relato de Caso. Revista de Saúde. 2019 Jan./Jun.; 10 (1): 37-43.

\begin{abstract}
Resumo
A osteonecrose da cabeça femoral é consequência de um infarto ósseo isquêmico que pode levar à destruição óssea, com dor e perda de função por conta da morte do tecido.

O lúpus eritematoso sistêmico e o uso prolongado de glicocorticoides apresentam-se como fatores importantes para o desenvolvimento desta patologia. Assim, o presente trabalho teve como objetivo relatar um caso de osteonecrose bilateral da cabeça femoral com manifestações pouco descritas na literatura e elucidar fatores preditivos para o desenvolvimento desta doença em pacientes com lúpus eritematoso sistêmico associado ao uso prolongado de corticoides. Adicionalmente, pretendeu-se relatar as manifestações clínicas e a terapêutica adotada para resolução deste problema. Pode-se concluir que o diagnóstico precoce desta patologia é de extrema importância e depende da avaliação clínica e de exames de imagens de alta sensibilidade, para que a área acometida possa er revascularizada e se evite a destruição articular e uma artroplastia total do quadril.

Palavras-chave: Corticoides; Lúpus eritematoso sistêmico; Osteonecrose.
\end{abstract}

\begin{abstract}
Femoral head osteonecrosis is a consequence of an ischemic bone infarction that can lead to bone destruction, with pain and loss of function due to tissue death. Systemic lupus erythematosus and glucocorticoids prolonged use are important factors for the development of this pathology. The aim of the present study was to report a case of bilateral osteonecrosis of the femoral head with manifestations poorly described in the literature and to elucidate predictive factors for the development of this disease in patients with systemic lupus erythematosus associated with corticosteroids prolonged use. In addition, it was intended to report the clinical manifestations and the therapeutics adopted to solve this problem. It can be concluded that the early diagnosis of this pathology is extremely important and depends on the clinical evaluation and high sensitivity imaging tests, so that the affected area can be revascularized and joint destruction and total hip arthroplasty is avoided.
\end{abstract}

Keywords: Corticoids; Osteonecrosis; Systemic lupus erythematosus.

\section{Introdução}

A osteonecrose (ONA) é uma entidade clínica de patogênese pouco definida que se caracteriza por deficiência de irrigação sanguínea, que resulta no colapso da arquitetura óssea, levando a perda da função, dor articular e destruição óssea. As causas da ONA envolvem a interrupção do suprimento vascular resultante de trauma local ou condições sistêmicas não traumáticas ${ }^{1}$. Os locais mais acometidos pela necrose avascular são os quadris, joelhos, tornozelos e ombros. A patologia pode manifestar de forma aguda, com dor intensa e precoce, contudo o mais comum é a forma crônica com longo período assintomático ${ }^{2}$.
A evolução da doença leva a destruição da articulação e comprometimento da cartilagem articular, além da deformidade e remodelação do formato ósseo. As causas de isquemia óssea estão relacionadas a fatores de risco dentre eles o lúpus eritematoso sistêmico (LES) e uso prolongado de corticoide. A classificação mais utilizada para determinar a localização e a extensão da área de necrose é a de Arlet e Ficat (Tabela 1)³.

A conduta terapêutica é definida de acordo com $\mathrm{o}$ estágio da doença dividindo-se em conservadora e cirúrgica. O tratamento conservador é realizado na minoria dos casos e inclui uso de analgésicos, bengalas, fisioterapia e repouso. Conforme o estágio evolutivo da doença no período do diagnóstico é possível reverter ou pelo menos frear o processo isquêmico

Afiliação dos autores: $\uparrow$ Discente da Universidade de Vassouras; Vassouras/RJ; Brasil.

\pm Discente da Universidade Federal Fluminense; Volta Redonda/RJ; Brasil.

$\S$ Docente da Universidade de Vassouras; Vassouras/RJ; Brasil

* Email de correpondência: alvesrobert34@gmail.com 


\begin{tabular}{cl} 
Estágio & \multicolumn{1}{c}{$\begin{array}{c}\text { Alterações radiológicas } \\
\text { da cabeça femoral }\end{array}$} \\
\hline I & \multicolumn{1}{c}{ Normal } \\
II & $\begin{array}{l}\text { Esclerose subcondral e cistos, com } \\
\text { esfericidade da cabeça mantida }\end{array}$ \\
III $\quad \begin{array}{l}\text { Sinal do crescente (seqüestro e colapso } \\
\text { parcial do segmento osteonecrótico) }\end{array}$ \\
IV $\quad \begin{array}{l}\text { Pinçamento articular, formação de } \\
\text { osteofóticos e deformação da cabeça }\end{array}$ \\
\hline
\end{tabular}

através de procedimento cirúrgico menos invasivo ${ }^{3}$. O procedimento cirúrgico que preserva o quadril natural é indicado no estágio I e no estágio II, utilizando o mecanismo de descarga do membro afetado através da técnica de descompressão medular da cabeça femoral, no intuito de diminuir a pressão intra-óssea e aumentar o fluxo sanguíneo regional, retardando a evolução da patologia. Em contrapartida, nos estágios mais avançados da doença, preconiza-se a artroplastia total do quadril (ATQ), quando a cabeça do fêmur e o acetábulo são substituídos por um dispositivo artificial ${ }^{4}$.

O lúpus eritematoso sistêmico é uma doença do tecido conjuntivo cuja base fisiopatológica está centrada na autoimunidade, pois apresenta a produção de vários auto-anticorpos devido a disfunção do sistema imune. A doença é caracterizada por reação inflamatória crônica em diversos órgãos e sistemas que evolui com manifestações multissistêmicas, intercalando períodos de exacerbações e remissões. A doença apresenta predomínio maior em mulheres jovens na fase reprodutiva do que em homens, numa proporção de 9:1. De etiologia não totalmente esclarecida, o desenvolvimento da doença está correlacionado a predisposição genética, fatores hormonais e ambientais ${ }^{5,6}$.

Muitas teorias foram propostas como prováveis causas da interrupção circulatória na ONA não traumática. Entre as enfermidades reumatológicas, o LES é a principal causa de osteonecrose da cabeça femoral (ONCF) não traumática. Diferentes fatores de risco associados ao desenvolvimento de ONCF, tais como o uso de corticoides, alcoolismo, anemia falciforme, vasculite, anticorpo antifosfolípides, distúrbios de coagulação e presença de fenômeno de Raynaud representam a via final comum de um grupo heterogêneo de estados patológicos, os quais culminam como fator preditivo para isquemia e necrose ósseas ${ }^{3}$.

O presente relato tem por objetivo descrever e discutir um caso de ostenecrose bilateral da cabeça femural com manifestações pouco descritas na literatura e identificar fatores preditivos para o desenvolvimento desta doença em pacientes com lúpus eritematoso sistêmico associado ao uso prolongado de corticoterapia, bem como definir conduta e tratamento adequado para resolução desta patologia.

Desta maneira, a realização do presente estudo justifica-se pela necessidade de produzir conhecimentos científicos acerca da ONA de pacientes com LES e uso prolongado de corticoides submetidos a procedimentos cirúrgicos, auxiliando na identificação precoce, no tratamento adequado e colaborando para a recuperação plena dos pacientes.

\section{Relato de caso}

Paciente do gênero feminino, 33 anos, branca, mãe de uma filha de oito anos, com diagnóstico de LES há aproximadamente doze anos. A paciente encontravase em uso regular de difosfato de cloroquina $250,0 \mathrm{mg} /$ dia, Lanzoprazol 30,0 mg/dia, prednisona $5,0 \mathrm{mg} / \mathrm{dia}$ (nos períodos de exacerbação da patologia utilizava 40,0 mg/dia).

Em Janeiro de 2017, compareceu à consulta com ortopedista com fortes dores no quadril esquerdo, dificuldade de caminhar e assentar. O referido médico realizou o exame físico, solicitou radiografia da bacia/ quadril e receitou o medicamento Deocil 10,0 mg/dia. Não foi relatada melhora clínica. Foi realizada uma radiografia da bacia e do quadril com resultado dentro da normalidade (Figura 1). Em seguida, a paciente realizou uma ressonância magnética nuclear (RMN) do quadril esquerdo, que revelou osteonecrose estágio II/III, com uma extensa lesão osteocondral, com contornos geográficos predominantemente hipointensa e heterogênea, apresentando halo periférico realce ao contraste paramagnético, acometendo a superfície articular da epífise femoral (Figura 2). Em meados de maio de 2017 foi realizada uma densitometria óssea do fêmur proximal direito que apresentou $-1,3$ desvios padrão, sendo considerado osteopenia (Figura 3).

No dia 23 de maio de 2017, realizou tratamento cirúrgico de descompressão da cabeça do fêmur esquerdo e, após processo cirúrgico, realizou sessões de 


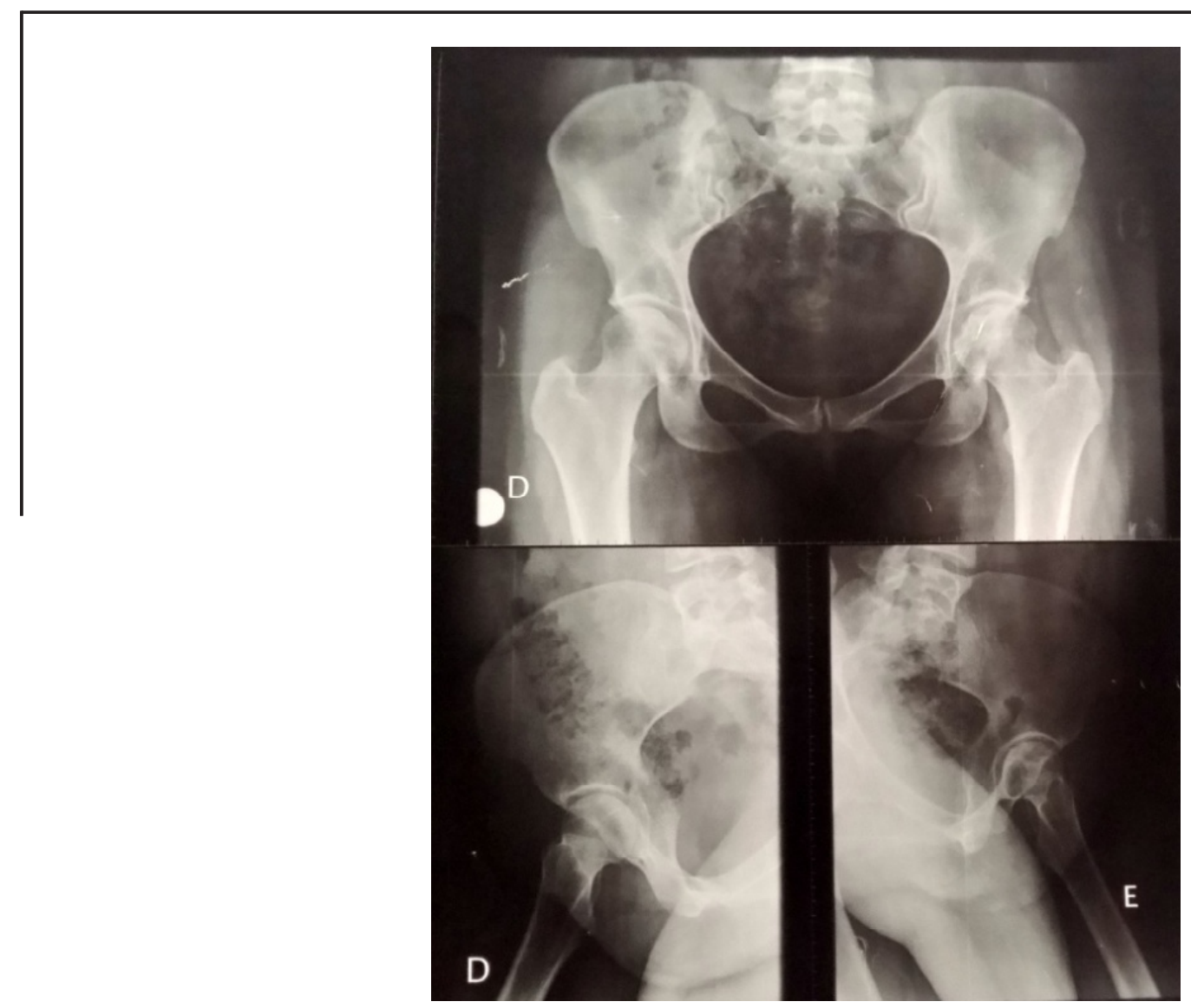

Figura1. Radiografia da bacia e do quadril dentro da normalidade (Fonte: acervo pessoal, 2017).

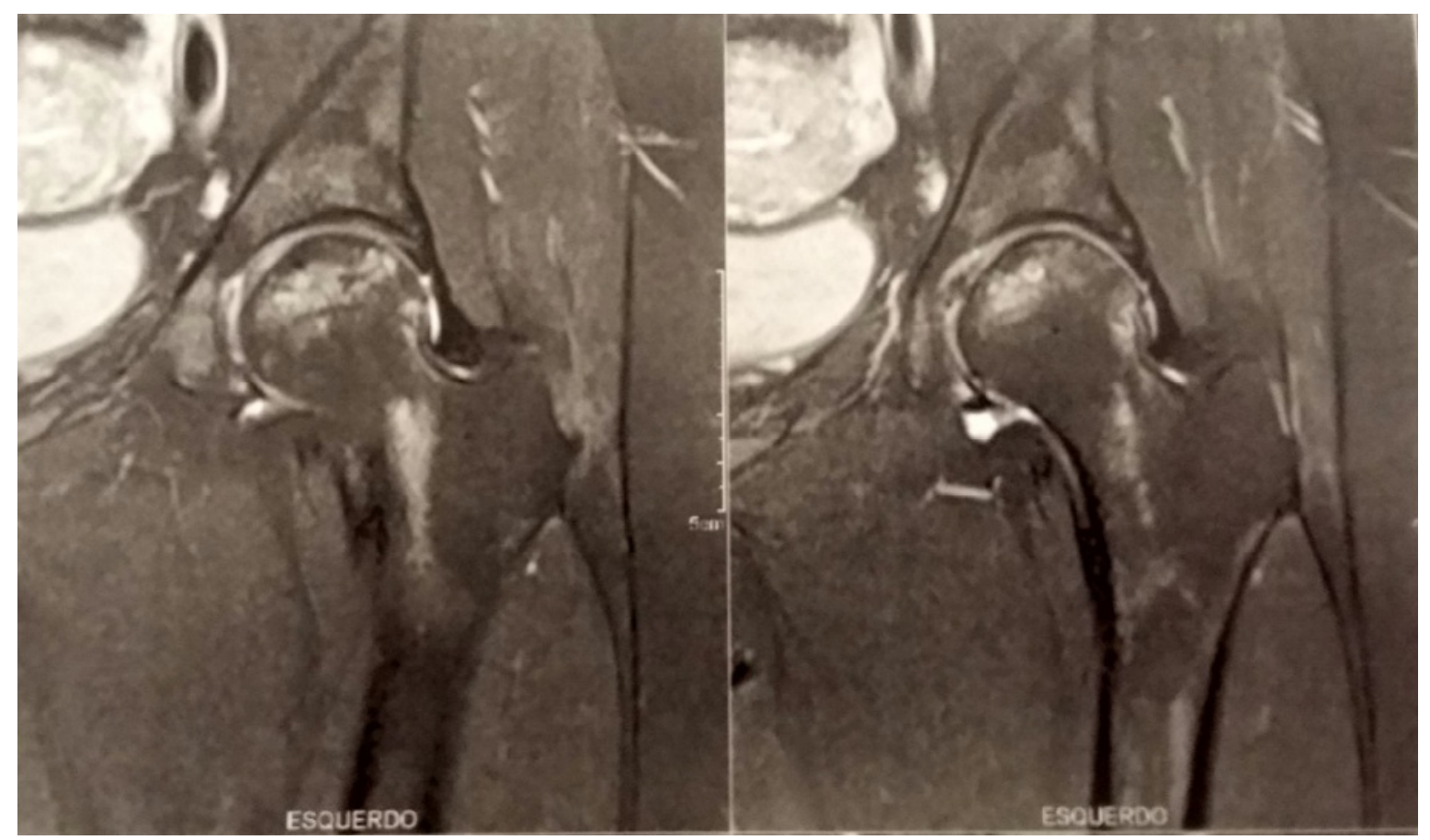

Figura 2. Osteonecrose Estágio II/III (Fonte: acervo pessoal, 2017). 


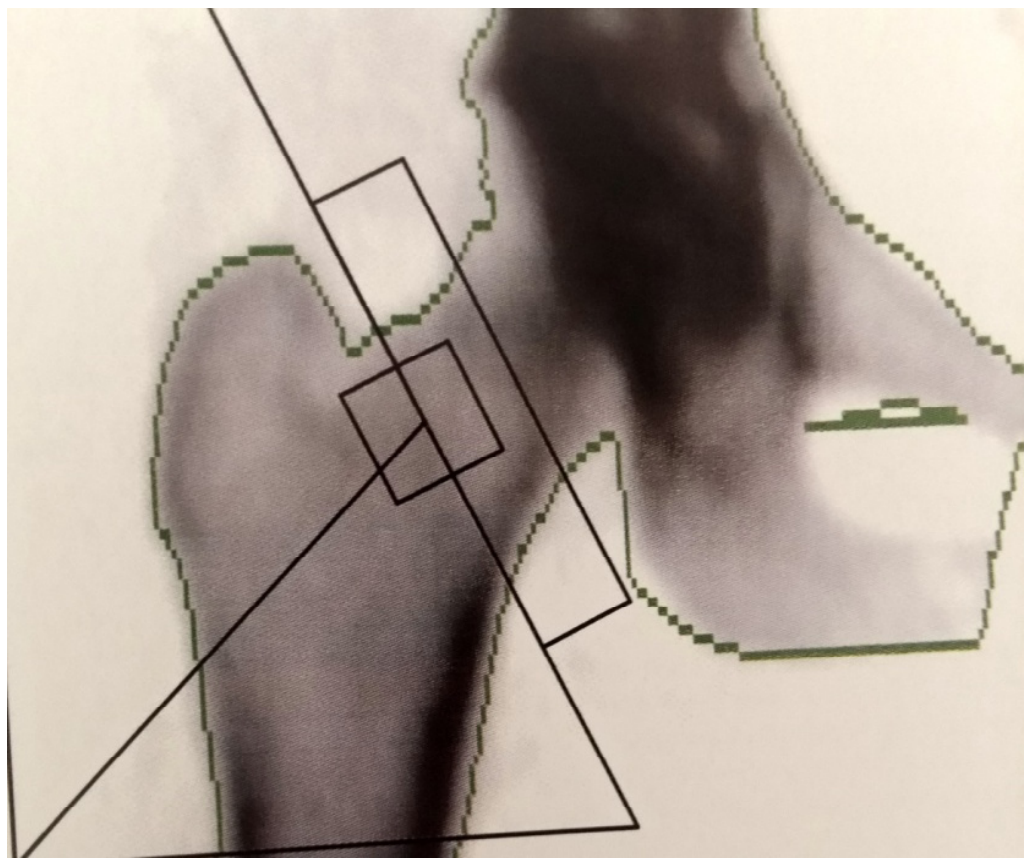

Figura 3. Densitometria óssea (Fonte: acervo pessoal, 2017).
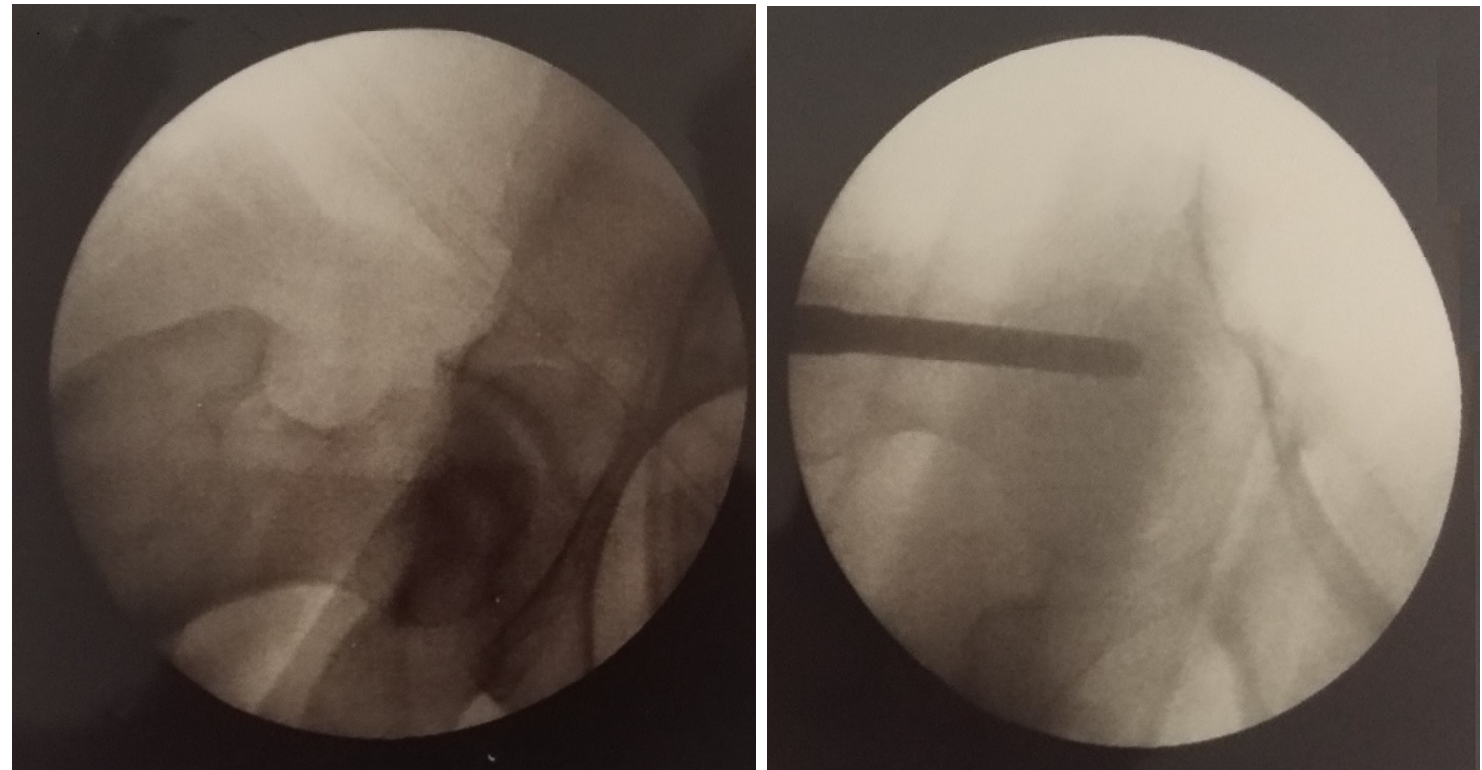

Figura 4. Radiografia da descompressão cirúrgica da cabeça do fêmur esquerdo. a: AP e b: perfil. (Fonte: acervo pessoal, 2017).

fisioterapia por 2 (dois) meses (Figura 4).

Em agosto de 2017 e em dezembro de 2017, devido a fortes dores que a acometeram, a paciente realizou radiografia de quadril e bacia, ficando constatada a esclerose na cabeça femoral do lado esquerdo, irregularidade no contorno dos ilíacos e grandes trocânteres (Figura 5).

Em junho de 2018 foi solicitada a realização de RMN do quadril direito e esquerdo. O exame de RMN do quadril direito realizado no dia 07 julho de 2018, permitiu levantar a hipótese diagnóstica de extensa lesão osteocondral localizado na epífise femoral $(2,8 \times 1,2 \times$ $2,3 \mathrm{~cm}$ ) apresentando edema ósseo reacional na porção periférica ao contraste com discreta irregularidade de esfericidade. A RMN evidenciou, ainda, área de edema ósseo medular na topografia da metáfise proximal do fêmur e bursite peritrocantérica (Figura 6).

$\mathrm{O}$ exame de RMN do quadril esquerdo realizado no dia 07 julho de 2018, revelou extensa lesão osteocondral localizada na epífise femoral $(2,7 \times 1,3 \mathrm{x}$ $2,1 \mathrm{~cm}$ ) associada a um edema ósseo medular na metade proximal do fêmur e bursite incipiente (Figura 7). 

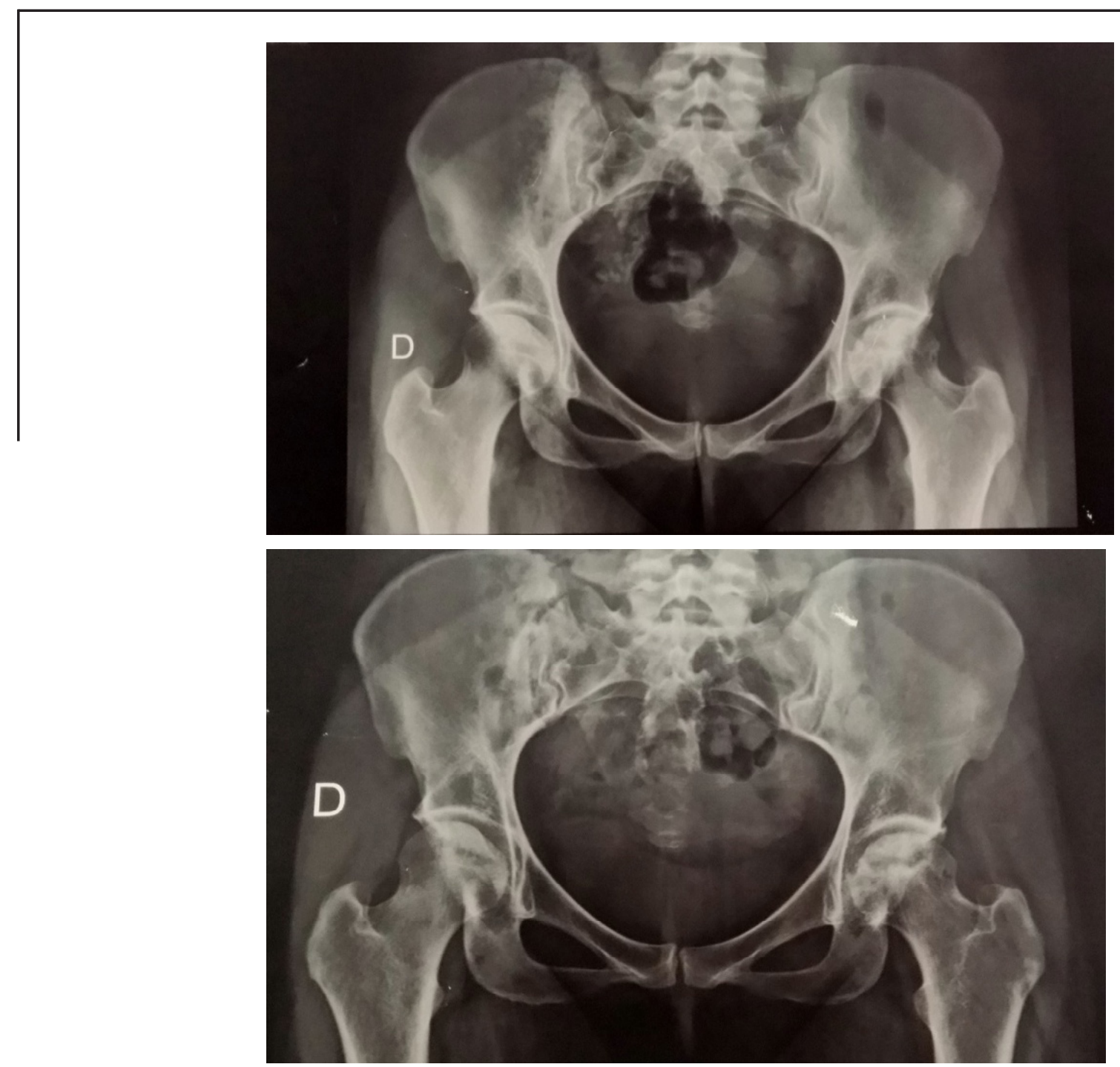

Figura 5. Radiografia de quadril e bacia. a: agosto de 2017 e b: dezembro de 2017 (Fonte: acervo pessoal, 2017).

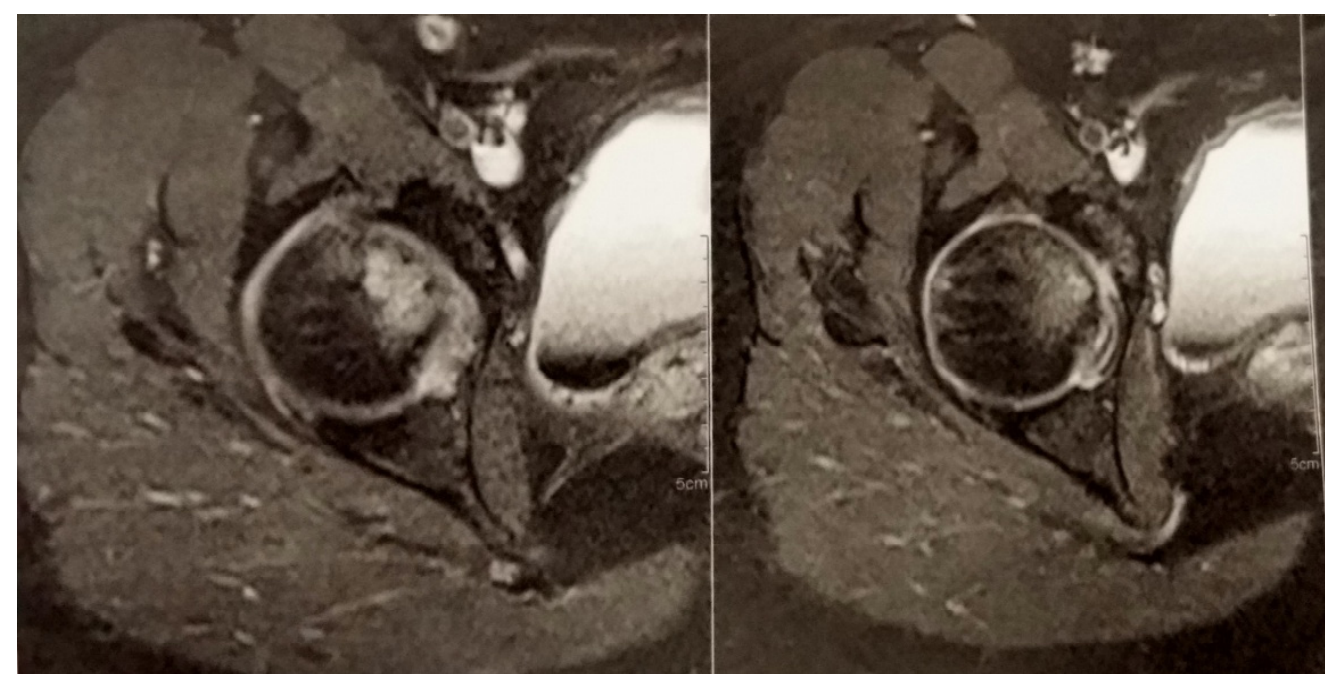

Figura 6. RMN do quadril direito (Fonte: acervo pessoal, 2018). 


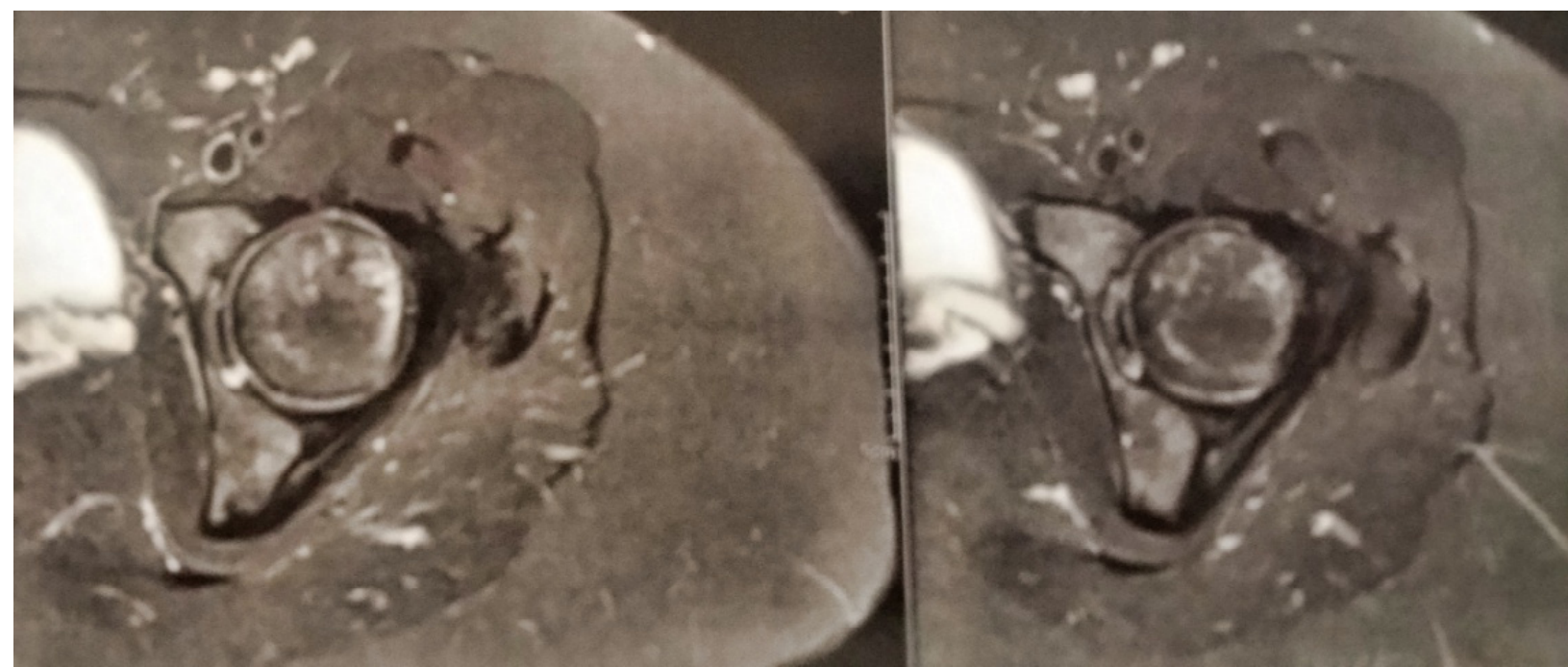

Figura 7. RMN do quadril esquerdo (Fonte: acervo pessoal, 2018).

Em virtude da extensão da necrose e do colapso ósseo, o tratamento proposto foi artroplastia total do quadril bilateral, sendo primeiramente recomendada a realização da ATQ do lado esquerdo.

\section{Discussão}

Inúmeras condições patológicas estão em conexão com a necrose da cabeça femoral, entretanto a patogênese não é conhecida em muitos casos. As causas da ONA incluem a interrupção do suprimento vascular proveniente de trauma local ou condições sistêmicas não traumáticas. Nos eventos não traumáticos incluemse o uso de corticoide sistêmico, desordens autoimunes, alcoolismo, doenças hematológicas, hiperlipidemias, leucemias, fatores ambientais, radiação e os idiopáticos ${ }^{1}$.

Em 1960, Dubois e Cozen foram uns dos primeiros pesquisadores a documentarem a associação entre LES e osteonecrose ${ }^{1}$. Outros pesquisadores ${ }^{7,8}$ acreditam que o uso de corticoides seria o fator de risco mais importante para o desenvolvimento de ONA em pacientes com LES, porém, esta patologia também tem sido descrita em pacientes que jamais fizeram uso de glicocorticoides ${ }^{8}$. Além disso, fatores associados à própria atividade do LES têm sido propostos como possíveis fatores preditivos para o desenvolvimento de ONA. Pesquisadores ${ }^{7}$ têm tido dificuldades em diferenciar os possíveis efeitos deletérios causados pelo uso de corticoides, das manifestações inerentes à doença ${ }^{9}$. No caso descrito neste trabalho, a referida paciente possui ambos os fatores de risco, o que dificulta a distinção do fator causal da ONA na cabeça do fêmur esquerdo.

Devido ao baixo custo e acessibilidade, a radiografia é o método de imagem utilizado na primeira abordagem ao paciente, apesar da baixa sensibilidade nos estágios iniciais da doença. Por outro lado, a RMN tem um papel de destaque no diagnóstico por conseguir revelar a patologia precocemente. Por ser um exame de boa sensibilidade, é considerado o exame padrão ouro para confirmar o diagnóstico de osteonecrose ${ }^{10}$.

A terapêutica baseia-se no estágio evolutivo da osteonecrose, de acordo com os critérios diagnósticos estabelecidos, dividindo-se o tratamento em conservador ou cirúrgico. Há uma grande divergência sobre o melhor método de tratamento na fase inicial da doença, devido ao fato dos pacientes acometidos serem, em sua maioria adultos jovens. Nestes casos, o tratamento de escolha no início da doença visa à manutenção da cabeça femoral ${ }^{11}$.

O objetivo principal do tratamento é a prevenção do colapso ósseo e o aparecimento de deformidades subsequentes. Sendo assim, torna-se fundamental o tratamento precoce quando a patologia se encontra nos seus estágios iniciais, em geral até o estágio II.

Diversas técnicas cirúrgicas têm sido desenvolvidas para prevenirem a evolução da patologia e o aparecimento de deformidades ${ }^{11}$. Estudos comparando a descompressão cirúrgica e os tratamentos conservadores revelaram uma taxa de sucesso superior em torno de $40 \%$ a favor do tratamento cirúrgico, em comparação ao método conservador ${ }^{3,12}$.

A descompressão da cabeça femoral é realizada fazendo uma perfuração de diâmetro maior ou várias perfurações menores na cabeça femoral para aliviar a pressão do osso e criar um canal para que novos vasos sanguíneos possam crescer e nutrir as áreas afetadas ${ }^{11,13}$. Por outro lado, estudos têm revelado que indivíduos portadores de osteonecrose que foram tratados de maneira conservadora tem menor taxa de sucesso na recuperação. Nestes casos, observou-se que $60 \%$ dos quadris apresentaram progressão da lesão ${ }^{13}$.

Observou-se que o tratamento realizado na paciente ora em destaque está de acordo com o 
descrito por diversos autores ${ }^{3,11,13}$. Apesar disto, tais procedimentos não foram resolutivos para o caso relatado, havendo progressão da necrose e continuidade de sintomas tais como fortes dores e dificuldade de deambulação.

Nos casos de grande colapso ósseo, área extensa de necrose, deformidade da cabeça femoral e restrição de movimento, tem-se optado pela artroplastia total do quadril (ATQ) com excelentes resultados. Em um estudo realizado na Suécia em 2012, constatou-se boa satisfação dos pacientes após um ano de realização de ATQ, que variou entre $82,4 \%$ a $93,4 \%{ }^{4}$.

Devidoo uso detécnicas modernas e minimamente invasivas, a ATQ é considerada um dos maiores avanços no tratamento das patologias ortopédicas e uma das cirurgias mais difundidas mundialmente, proporcionando aos pacientes uma rápida recuperação e o pronto retorno às atividades cotidianas ${ }^{4}$.

Em relação ao caso exposto, é notório que com a extensão da necrose, e o extremo desconforto e as limitações da paciente, a realização da artroplastia total do quadril seria o tratamento ideal e resolutivo, considerando o insucesso das abordagens anteriores.

\section{Considerações finais}

Conclui-se, portanto que o diagnóstico precoce da necrose óssea avascular em pacientes na vigência de LES e uso prolongado de glicocorticoides é de extrema importância. Para se obter um diagnóstico conclusivo, são necessários, além da avaliação clínica, exames de imagens de alta sensibilidade, tais como a ressonância magnética nuclear, que identificam as regiões afetadas pela osteonecrose. Uma vez realizado o diagnóstico de necrose avascular, a terapêutica visará restabelecer a revascularização da área acometida e impedir a progressão da patologia, de modo a evitar a destruição articular e uma artroplastia total do quadril.

\section{Referências}

1. Marcelina E, Sella C, Rosenilda M, Carvalho P De, Sato EI. Osteonecrose em Pacientes com Lúpus Eritematoso Sistêmico (*) Osteonecrosis in Systemic Lupus Erythematosus Patients. 2005;1-8.

2. Cristina S, Fialho S. Atividade de doença como principal fator de risco para osteonecrose no lúpus eritematoso sistêmico de diagnóstico recente. 2006;

3. Neves J, Carvalho M, Araújo A, Batista M, Fachada N, Lima J, et al. Necrose Asséptica da cabeça do fémur. [citado 19 de junho de 2018]; Available at: http://www.spot.pt/media/90343/Necrose-Asséptica-da-cabeçado-fémur.pdf

4. Roberto Galia C, Valter Diesel C, Guimarães MR, Ribeiro TA. Atualização em artroplastia total de quadril: uma técnica ainda em desenvolvimento. Rev Bras Ortop [Internet]. 2017 [citado 1 de agosto de 2018];52:521-7. Available at: http://dx.doi.org/10.1016/j.rbo.2016.09.013

5. Borba EF, Latorre LC, Brenol JCT, Kayser C, da Silva NA, Zimmermann $\mathrm{AF}$, et al. Consenso de lúpus eritematoso sistêmico. Rev Bras Reumatol.
2008;48(4):196-207.

6. Paula M De, Santiago B, Castelo N, Dantas B, Bezerra S, Carvalho F De. Atividade, Gravidade e Prognóstico de pacientes com Lúpus Eritematoso Sistêmico - antes , durante e após prima internação Systemic Lupus Erythematosus patients activity, gravity and prognosis - before , during. 2014;2(2):65-73.

7. Fukushima W, Yamamoto T, Takahashi S, Sakaguchi M, Kubo T, Iwamoto $\mathrm{Y}$, et al. The effect of alcohol intake and the use of oral corticosteroids on the risk of idiopathic osteonecrosis of the femoral head: a case-control study in Japan. Bone Joint J [Internet]. 2013;95-B(3):320-5. Available at: http:// www.ncbi.nlm.nih.gov/pubmed/23450014

8. Pereira ALC, Bolzani FCB, Stefani M, Charlín R. Uso sistêmico de corticosteróides: Revisão da literatura. Med Cutan Ibero Lat Am. 2007;35(1):35-50.

9.Foram R. Necrose avascular da cabeça femoral induzida por corticóide : estudo experimental *. 1999;34(021)

10. Ribeiro DS, Araújo Neto C De, D’Almeida F, Galvão VL, Santiago MB. Achados de imagem das alterações musculoesqueléticas associadas ao lúpus eritematoso sistêmico. Radiol Bras. 2011;44(1):52-8.

11. Hofmann S, Kramer J, Plenk H. Die osteonekrose des hüftgelenks im erwachsenenalter. Radiologe. 2002;42(6):440-50.

12. Fonseca F. Uso de aloenxerto osteocondral em paciente com necrose avascular do joelho secundária a lúpus. Rev Bras Ortop [Internet]. 2017; (x x):4-8. Available at: http://dx.doi.org/10.1016/j.rbo.2017.06.016

13. Rp G, Juliana RMJ, Vaz M, Simões R, Meves R, Wm B. Projeto Diretrizes Necrose Asséptica da Cabeça Femoral no Adulto Projeto Diretrizes. 2012 [citado 19 de junho de 2018];1-8. Available at: https://diretrizes.amb.org. br/_BibliotecaAntiga/necrose asseptica_da_cabeça_femoral_no_adulto.pdf 